\title{
CÉSAR SONHA COM UM MUNDO EM QUE NÃO ATRAVESSOU O RUBICÃO?
}

Doutoranda em Filosofia PUC-RIO - Bolsista CAPES

\begin{abstract}
Resumo: Este trabalho se propõe a tomar a ficção de Philip K. Dick a partir da ideia leibniziana dos infinitos mundos possíveis. Trata-se de pensar as distopias enquanto retas tangentes à curva do mundo atual, de modo que não constituam uma contradição em relação a esse mundo, mas, tocando-o em algum ponto, sejam seu máximo desvio a partir de uma mínima diferença.
\end{abstract}

Palavras-chave: Leibniz, Philip K. Dick, Distopia, Andróides.

Philip K. Dick parece reproduzir no espaço pós-catastrófico de Androides sonham com ovelhas elétricas? o instante fora do tempo, da metafísica de Leibniz, em que infinitos mundos possíveis, variáveis apenas pela quantidade de essência ou grau de perfeição que contêm, coexistem no intelecto divino. Tal pensamento vertiginoso, que as criaturas experimentam no momento de hesitação garantido pelo livre arbítrio, ocorre a Rick Deckard, caçador de androides em uma terra arrasada pela guerra nuclear, quando dirige seu carro para fora da área de segurança, ao norte da cidade de San Francisco. Estar fora de um perímetro seguro significava estar exposto a uma maior concentração da poeira radioativa que havia tomado a superfície do planeta e cujos efeitos foram o extermínio dos animais (a começar pelas corvjas) e o novo impulso ao programa de colonização de Marte (já em curso antes da guerra). Os humanos que sobreviveram à catástrofe e permaneceram na Terra estavam sob um risco constante: a poeira poderia provocar modificações genéticas que os tornasse 
biologicamente inaceitáveis. Passavam a ser classificados como Especiais, humanos que cessavam de fazer parte da humanidade. A emigração para Marte fora alavancada, portanto, por duas formas de gradação de humanidade, ambas negativas, por assim dizer: a ameaça de se tornar um Especial e a construção de robôs humanoides (ou androides orgânicos) para auxiliar na colonização.

Rick havia aposentado, naquele dia, seis androides que fugiram do projeto colonizador interplanetário e tentavam se disfarçar entre os humanos. As pequenas variações entre as formas de humanidade ou, inversamente, de maquinicidade, perturbavam o caçador de androides. A função que ele cumpria dependia de uma ausência de empatia com os robôs, ou, dito de outra forma, aos caçadores de androides cabia manter a diferença, ainda que cada vez menor, entre humanos e máquinas; não uma diferença absoluta, portanto, mas infinitesimal. Na região fora da área de segurança coberta pela poeira radioativa, Rick julgou ter se fundido com Wilbur Mercer, uma experiência a que todo humano tinha acesso na sua própria casa através da caixa de empatia. Bastava apertar os manetes para entrar em contato com Mercer, um deus sisifiano que deixa um mundo tumular e sobe uma colina num ciclo sem fim, e com todos os demais humanos acoplados à máquina. Ora, a caixa de empatia é o ponto de vista monádico, aquele que contém em si a relação com todas as coisas. Mas Rick o havia acessado sem a mediação de um mecanismo. Passado o transe, avistara uma protuberância entre as pedras, uma dobra de poeira que parecia se mover. Entrou em êxtase quando percebeu que se tratava de um sapo, animal extinto há anos e criatura sagrada para Mercer. Como o bicho se matizava totalmente à textura radioativa da superfície, Rick pensou que talvez o sapo tivesse evoluído, se adaptado ao novo clima, como se adaptara a todos os climas anteriores. "Encontrei-o porque vi com os olhos de Mercer", pensou.

Então é isso que Mercer vê, Rick concluiu enquanto amarrava caprichosamente a caixa de papelão fechada - amarrou-a várias vezes. Vida que não podemos mais distinguir; vida cuidadosamente enterrada até a testa na carcaça de um mundo morto. Em cada cinza do universo Mercer provavelmente distingue a vida mais imperceptível. Agora eu sei, pensou. E 
uma vez que vi através dos olhos de Mercer, possivelmente nunca vou parar'.

Rick voltou para a casa e mostrou o sapo para a mulher. Ela apalpou o abdômen do bicho e encontrou um pequeno painel de controle. Tratava-se de um sapo elétrico.

Humanos associados a animais elétricos - essa é apenas uma das formas de agenciamento entre máquina e natureza na distopia de Philip K. Dick. As diferentes combinações entre homens, Especiais, androides, animais e animais elétricos produzem um contínuo que permeia e torna fluida a distinção proposta por Leibniz entre autômato natural e autômato artificial. No Sistema novo da natureza e da comunicação das substâncias, Leibniz argumenta que essa diferença não seria apenas de grau, mas também de gênero, pois uma máquina construída pela arte humana não é máquina em cada uma de suas partes; o dente de uma roda de latão, pondera no $\S 64$ da Monadologia, tem partes que não mais identificam a máquina para o uso da qual está destinada a roda, enquanto as máquinas da natureza são máquinas inclusive em suas menores partes, até o infinito. Segue-se que as máquinas naturais estão protegidas de todos os acidentes, afirma Leibniz no $\S 10$ do Sistema novo, é impossível destruí-las, sempre permanecem as mesmas, sendo apenas transformadas por diferentes modos de dobramento e desdobramento. Na distopia de Philip K. Dick, os mundos orgânico e inorgânico deixam de ser noções distintas e se tornam gradações. O caçador de androides Phil Resch, que acreditava ele próprio ser um androide por sua deficiência de empatia com os robôs humanoides, pede que Rick lhe aplique o teste de empatia VoigtKampff para saber se é só uma máquina com estruturas de memórias falsas. Phil mendiga alguma humanidade para Rick ao argumentar que possui um animal de verdade, um pequeno esquilo que mantém em uma gaiola. É como se a associação com o animal lhe fosse a garantia de ser um corpo vivo inclusive em suas menores partes. Rick, por sua vez, tem uma ovelha elétrica. Tudo se passa como se suas partes infinitamente pequenas fossem mecânicas na execução de sua atividade de caçador de androides. No entanto, a empatia que desenvolve por eles o obriga a comprar um

\footnotetext{
${ }^{1}$ DICK, P. K. Androides sonham com ovelhas elétricas?, p. 228.
} 
animal de verdade, uma cabra, para que possa se diferenciar das percepções maquínicas e finalizar sua tarefa. Já John Isidore, um Especial que trabalhava como motorista numa empresa de conserto de animais falsos, confundiu a morte de um gato verdadeiro com o desgaste técnico de um animal elétrico. É a ironia de sua condição: as transformações genéticas provocadas pela poeira radioativa lhe negam a condição de humano, ainda que permaneça um ser orgânico capaz de percepções. Por fim, a androide Rachael, antes de ser submetida ao teste de empatia, aparece associada a uma coruja elétrica, compondo, assim, um grau mínimo de humanidade, ou, dito de outra forma, um grau máximo de maquinicidade. Tais combinações problematizam o teste de empatia aplicado por Rick, pois a questão não se resume em saber se as máquinas se tornaram tão potentes a ponto de serem confundidas com humanos, mas no fato de que as diferentes formas de agenciamento diluem, tornam equívoca essa oposição.

Apesar de apostar numa diferença de gênero entre natureza e máquina, Leibniz introduz algo entre os dois polos ao suprimir o pseudo-limite da morte, que não é para ele senão uma redução da vida. Não há morte nem geração, argumenta Leibniz no § 73 da Monadologia: o que chamamos de gerações são desenvolvimentos e crescimentos e o que chamamos de mortes são envolvimentos e diminuições. E é particularmente o destino das almas quando da morte dos animais que the interessa no $\S 7$ do Sistema novo. Tanto a alma quanto o animal são conservados, conclui Leibniz, embora a destruição de suas partes mais notáveis torne tal fenômeno pouco perceptível aos nossos sentidos, como também o era antes do nascimento do animal. Disso parecem ter clareza os androides de Philip K. Dick. "Qual a sensação de ter um filho?", pergunta-se a androide Rachael. "Pensando bem, qual é a sensação de nascer? Nós não nascemos; não crescemos; em vez de morrer de doença ou de velhice, desgastamos com o uso como formigas" ${ }^{2}$. Os robôs humanoides seriam a imagem das fluxões que se interpõem incessantemente entre duas noções distintas. Neste sentido, podemos dizer que é como se Leibniz desdobrasse (des-envolvesse, ex-plicasse) sua distinção entre o que é natural e o que é artificial numa diferença infinitesimal através da negação de um ponto de vista privilegiado, isto é, da negação de uma origem e de um fim.

\footnotetext{
${ }^{2}$ DICK, P. K. Androides sonham com ovelhas elétricas?, p. 186.
} 
Aqui não há mais volta, estamos no labirinto do contínuo. A forma como um conhecimento distinto se desdobra em um pensamento vertiginoso parece fundá-lo e alimentá-lo. É esse o caso dos testes de empatia aplicados pelo caçador de androides, na medida em que explicitam e problematizam a gradação que as diferentes combinações de elementos naturais e artificiais produzem. No § 24 do Discurso de Metafísica, Leibniz diz que um conhecimento distinto é o que permitiria, por exemplo, identificar a diferença entre o verdadeiro e o falso ouro por intermédio de marcas capazes de atestar sua legitimidade. No entanto, essa verificação é problemática, pois ela própria exigiria uma definição, e assim numa sequência interminável, o que leva Leibniz a afirmar que o conhecimento distinto tem graus, ou, dito de outra forma, há, em última instância, apenas ideias mais ou menos confusas. O conhecimento distinto seria apenas um limite, pois tem como condição o conhecimento adequado de todas as marcas e elementos constitutivos ao infinito. Nossos pensamentos nascem da relação de todas as coisas entre si, diz Leibniz, mas o ponto de vista para perceber a totalidade do mundo é dado pelo corpo ao qual a alma está ligada; e onde há corpo, há confusão.

Seguir, pois, a série infinita de variações dos estados das coisas não garante uma razão suficiente para sua existência. Por mais que possamos retroceder a estados anteriores, jamais encontraremos nesses estados uma razão completa que explique por que existe um mundo e por que ele é do modo que é. Daí Leibniz sugerir que passemos da necessidade física, que determina as coisas posteriores do mundo pelas anteriores, para a necessidade metafísica. Uma vez que as coisas existentes não podem derivar de nenhuma outra coisa exceto de coisas existentes, deve existir um ser metafisicamente necessário, diverso da pluralidade das coisas, diverso do mundo que admitimos não ser metafisicamente necessário, um ser cuja essência é a existência, Deus. A forma como Leibniz prova a existência de Deus é também uma prova da existência dos mundos possíveis. Todas as coisas que expressam essência ou realidade possível, antes ou fora da existência, não são imaginárias ou ficcionais. Elas existem, diz Leibniz, "em um certo reino das ideias, por assim dizer, ou seja, no próprio Deus, a fonte de toda essência e da existência de todo o resto" ${ }^{\prime 3}$. Estamos diante de uma variação da máxima de

\footnotetext{
${ }^{3}$ LEIBNIZ, G. W. A monadologia e outros textos, p. 73.
} 
Dostoiévski de que se Deus está morto, tudo é permitido. Leibniz nos diz que se Deus existe, os mundos possíveis também existem.

A passagem dos mundos possíveis no intelecto divino à forma que assumem na indiferença da vontade tem uma dimensão geométrica. Deus faz com que nossas vontades tendam ao bem, mas nossas escolhas não são necessárias. A vontade está na indiferença, diz Leibniz no § 30 do Discurso de Metafísica, na medida em que se opõe à necessidade e tem o poder de proceder de modo diverso ou ainda de suspender a ação, permanecendo ambos, a ação e seu contrário, possíveis. Tal indiferença não deve ser confundida com a indiferença paralisante associada ao sofisma do asno de Buridan, como explica Déborah Danowski no artigo "Indiferença, simetria e perfeição segundo Leibniz". O caso em que um asno faminto fica paralisado diante de duas medidas idênticas de aveia, numa versão da história, e de aveia e de água, em outra, seria impossível, pois a simetria perfeita de dois objetos quaisquer dependeria da simetria de toda a série de relações que eles exprimem. A indiferença do equilíbrio viola não apenas o princípio dos indiscerníveis, segundo o qual não podem existir duas coisas que difiram apenas numericamente, mas a própria indiferença da vontade; aprisiona o asno em uma alternativa estreita, enquanto a hesitação garantida pelo livre arbítrio é uma forma de produzir o pensamento vertiginoso dos mundos possíveis.

\author{
Mesmo que não nos apercebamos disso, ao considerar dois \\ possíveis objetos \\ de nossa vontade estamos na verdade percebendo toda a série \\ de substâncias \\ expressas mais ou menos obscuramente por cada um desses \\ objetos. Estamos \\ percebendo a totalidade dos dois mundos possíveis distintos que \\ se tornariam reais caso escolhêssemos uma ou outra \\ alternativa ${ }^{4}$.
}

Dos infinitos mundos possíveis, o mundo escolhido por Deus é aquele através do qual o máximo de essência ou de possibilidade é levado a existir. Leibniz o compara a

\footnotetext{
${ }^{4}$ DANOWSKI, D. “Indiferença, simetria e perfeição segundo Leibniz", p. 61.
} 
uma linha geométrica de simples construção e rica em fenômenos. É aqui que os labirintos do contínuo e da liberdade parecem se sobrepor e que podemos dizer, como o caçador de androides, que temos a visão de Mercer; não a visão divina de um sapo verdadeiro, animal extinto, mas a visão humana de um sapo elétrico, uma gradação de si mesmo. Um César que sonha com um mundo em que não atravessou o Rubicão, ou seja, com uma versão extinta de si, é um César que sonha que seja possível traçar uma curva que exprima o contorno do mundo, na medida em que não há rosto cujo contorno não faça parte de uma linha geométrica, diz Leibniz no § 6 do Discurso de Metafísica, uma curva, portanto, que seja ela própria feita das pequenas variações a que se devem os mundos extintos. Pensar a curva do mundo atual a partir da série dos mundos menos perfeitos do Deus leibniziano é pensá-la a partir de suas infinitas retas tangentes, a partir, portanto, de suas distopias, que não são uma contradição em relação a esse mundo, mas tocam-no em algum ponto, são seu máximo desvio a partir de uma mínima diferença.

No Discurso de Metafísica, Leibniz define a substância individual pelo in-esse, por estar o predicado no sujeito; a ficção científica, por sua vez, se dá nas infinitas regiões limítrofes deste mundo, define-se pelo inter-esse, pelo existir no limiar. Pensar como se escreveria a curva desse mundo a partir de suas distopias é, portanto, mais do que pensar uma possível atualização de seus limites, é pensá-lo como fundado na variação, nos mínimos quadrados, no inter-esse. Estamos diante da forma geométrica da indiferença da vontade: um plano que, como dizem Deleuze e Guattari nos Mil Platôs, longe de reduzir a dois o número de dimensões das multiplicidades, as faz coexistir como se fosse possível achatar todas as suas dimensões conservadas. As distopias permitem que os mundos possíveis coexistam sincronicamente e não diacronicamente, isto é, a curva do mundo atual não exprime sua evolução no tempo, mas a variação das apercepções em função da variação das percepções (penso em um plano cartesiano em que o eixo vertical é dado pelas apercepções e o horizontal, pelas percepções).

No § 21 da Monadologia, Leibniz compara o aturdimento decorrente de uma multiplicidade de pequenas percepções com a vertigem que sobrevém quando se gira continuamente em um mesmo sentido várias vezes seguidas. Se não houvesse em nossas percepções nada de distinto, a alma não diferiria de uma simples mônada, o 
que significa que a curva do mundo atual tenderia a ser uma reta horizontal. Por outro lado, aquilo que Leibniz combate em Locke, a identidade enquanto identidade da consciência, nada mais é do que a curva tendendo a ser uma reta vertical. Mas Leibniz reconhece que mesmo os animais possuem percepções distintas em razão dos órgãos sensíveis aos raios de luz e às "ondulações de ar". Ora, se o arranjo entre as pequenas percepções e as apercepções é dado pela sensibilidade à luz, o plano em que o mundo atual é traçado a partir de suas distopias é um ramo da óptica e há todo um espectro de substâncias sensíveis à luz capazes de exprimir a curva deste mundo - das plantas, pela fotossíntese, ao cinema, cujo protótipo é o brinquedo do fenacistiscópio (o movimento vertiginoso de uma série de imagens sobre um eixo).

O sistema de Leibniz marca a introdução, na filosofia, da noção de ponto no infinito, aspecto geométrico de que se vale a óptica para exprimir o fenômeno da projeção. Alma e corpo são multiplicidades ontologicamente disjuntas, cada qual se organiza segundo suas próprias leis, mas são também multiplicidades paralelas.

Significa dizer que há entre elas separação e analogia; são duas sequências que não se reencontram jamais, mas possuem mesma direção. É o que Michel Serres diz ser o máximo de identidade na diferença ontológica ou o máximo de diferença na identidade legisladora. É somente em Deus, ou seja, no infinito, que as multiplicidades paralelas concorrem entre si, de modo que as leis que organizam cada sequência são aplicáveis umas nas outras. Dito de outra forma, é esse ponto no infinito que as faz ao mesmo tempo separadas (sem ponto comum no finito) e idênticas (de mesma direção), é ele que dá a razão de uma analogia na diferença. Deus, no infinito, explica Serres em Le système de Leibniz et ses modèles mathématiques, amarra as separações e desamarra as identidades. A diferença entre a visão de Deus e a visão das criaturas é aquela que existe entre iconografia e cenografia, isto é, o mundo está estruturado em sequências paralelas aos olhos de Deus e aos olhos das criaturas aparece como um feixe de linhas convergentes na posição em que ocupam. As linhas concorrentes em um ponto finito e as linhas paralelas de mesma direção são de mesma ordenação, a diferença é apenas a distância, finita ou infinita, do ponto de intersecção. Ter, enquanto humano sobrevivente da catástrofe nuclear, a visão de Mercer é, portanto, ter a visão da analogia na diferença não entre alma e corpo, mas das curvas de segunda ordem ou seções planas de um cone. A elipse, a hipérbole e a parábola são gradações 
intermediárias entre a reta e o círculo, se assemelham de algum modo a seus conceitos-limite, são sua projeção sobre o plano que corta a estrutura cônica. Nada parece mais dessemelhante entre si do que essas figuras, mas sua anamorfose recobre seu isomorfismo, diz Serres.

Tomar as distopias como retas tangentes ao mundo atual (retas que, em matemática, efetivamente exprimem funções de menor grau ou potência - os mundos menos perfeitos de Leibniz) é uma forma de passar do objeto da catástrofe - o sapo ao fundo - a poeira radioativa, que é, afinal, o elemento de intensificação do contínuo na distopia de Philip K. Dick (com o aparecimento dos Especiais e o desenvolvimento dos androides e dos animais elétricos). O feixe de retas tangentes tem a indistinção da poeira que se dobra e assume os traços distintos da curva - de um sapo. As distopias, ou as retas tangentes, são uma forma de preencher o mundo, de refutar a ideia de máximo e mínimo, de indivisível e de todo (aquilo a que falta partes e que não pode ser parte de outro). O máximo é o máximo de diferença limitado pela possibilidade de combinação que deve ser conservada. Que a curva desse mundo seja apenas uma protuberância no feixe de distopias permite pensar, como propõe Serres, uma verdadeira filosofia da finitude, oposta à do dogmatismo disfarçado, que, crente de ter encontrado uma região limítrofe, inalcançável, não faz mais do que, nas palavras de Serres, redesenhar o lugar de Deus.

[...] le dogmatique dit, là est la fin, le terme; dès lors, à l'extérieur de la limite, il n'y a pas de connaissance, mais à I'intérieur, elle est totale, au moins à terme. Le philosophe de la finitude dit : il y a limite, mais il y a problème sur la limite. Je vais vers elle sûrement, à tâtons et avec des reculs, mais il n'est pas probable que je l'atteigne. C'est sur un espace gnoséologique toujours ouvert et sans point privilégié que se construit cette philosophie : c'est strictement le cas du leibnizianisme. A Révolution Copernicienne pluraliste correspond exactement une philosophie des limites inassignables ${ }^{5}$.

É com as distopias que tateamos o limite, tal como o faz Philip K. Dick ao narrar a atração do caçador de androides Rick pela androide Rachael. "Eu não estou viva!

\footnotetext{
${ }^{5}$ SERRES, M. Le système de Leibniz et ses modèles mathématiques, p. 253-254.
} 
Você não está indo pra cama com uma mulher" ${ }^{\prime \prime}$, diz a androide. Tatear o limite é tatear, como o faz Rick, o que não está nem vivo nem morto, não é nem homem nem mulher, nem orgânico nem inorgânico, é, enfim, tatear a gradação que há entre eles. Este ato é talvez o ponto de partida para a revolução astrofísica que Serres pede à filosofia contemporânea, a saber, não se trata mais de, com Copérnico, passar de uma desordem aparente para uma ordem real, mas de conceber a desordem real como mais fundamental que a ordem aparente.

\section{REFERÊNCIAS}

DANOWSKI, D. "Indiferença, simetria e perfeição segundo Leibniz". Kriterion, Belo Horizonte, n. 104, p. 49-71, dez. 2001.

DELEUZE, G.; GUATTARI, F. Mil platôs: capitalismo e esquizofrenia. Tradução: Suely Rolnik. 2. ed. São Paulo: Editora 34, 2012. v. 4.

DICK, P. K. Androides sonham com ovelhas elétricas? Tradução: Ronaldo Bressane. São Paulo: Aleph, 2014.

LEIBNIZ, G. W. A monadologia e outros textos. Tradução: Fernando Luiz Barreto Gallas e Souza. São Paulo: Hedra, 2009.

Discurso de metafísica e outros textos. Tradução: Marilena Chavi e Alexandre da Cruz Bonilha. São Paulo: Martins Fontes, 2004a.

Novos ensaios sobre o entendimento humano. Lisboa: Edições Colibri,

2004b.

SERRES, M. Le système de Leibniz et ses modèles mathématiques. Paris: Presses Universitaires de France, 1990.

\footnotetext{
${ }^{6}$ DICK, P. K. Androides sonham com ovelhas elétricas?, p. 186.
} 
César sonha com um mundo em que não atravessou o rubicão? - Raquel de Azevedo

AnaLógos, Rio de Janeiro, v. 1, 2016, p. 12-21 